\title{
Plasma and Red Blood Cells Concentration Profiles of Ketamine after Single Intravenous Administration in an Anaesthetic Protocol in Horses
}

\author{
Francesca Sori, Noemi Romagnoli, Domenico Ferrara, Anna Zaghini, Paola Roncada* \\ Department of Veterinary Medical Sciences, School of Agriculture and Veterinary Medicine, \\ Alma Mater Studiorum, University of Bologna, Bologna, Italy \\ Email: " paola.roncada@unibo.it
}

Received December 6, 2012; revised January 15, 2013; accepted February 15, 2013

Copyright (C) 2013 Francesca Sori et al. This is an open access article distributed under the Creative Commons Attribution License, which permits unrestricted use, distribution, and reproduction in any medium, provided the original work is properly cited.

\begin{abstract}
The aim of this study was to describe the concentration profile of ketamine in plasma and red blood cells following an intravenous (IV) bolus in the horse. Ten healthy standardbred horses (two males and height females) $7.7 \pm 4.6$ (mean value $\pm \mathrm{SD}$ ) years old and weighting $380 \pm 21 \mathrm{~kg}$ (mean value $\pm \mathrm{SD}$ ) were recruited. The horses were premedicated with acepromazine $\left(0.04 \mathrm{mg} \cdot \mathrm{kg}^{-1} \cdot \mathrm{IV}\right)$. Fifteen minutes later they received romifidine $\left(0.08 \mathrm{mg} \cdot \mathrm{kg}^{-1} \cdot \mathrm{IV}\right)$, and 5 minutes after they were administered midazolam $\left(0.06 \mathrm{mg} \cdot \mathrm{kg}^{-1} \cdot \mathrm{IV}\right)$. Immediately, anaesthesia was induced by ketamine $(2.2$ $\mathrm{mg} \cdot \mathrm{kg}^{-1} \cdot \mathrm{IV}$ ). Venous blood samples were collected at scheduled time points. Plasma and red blood cells (RBCs) concentration of ketamine was assayed using a high performance liquid chromatographic method (HPLC/UV-DAD). The high mean recovery rates, the high sensitivity, the good linearity, suggest a clinical applicability of the analytical method. A bicompartmental model resulted as the most appropriate to describe the ketamine concentration-time profile for both plasma and RBCs. The fitted regression line between ketamine plasma concentrations and RBC concentrations supports the good correlation between ketamine concentrations in plasma and in RBCs. The kinetic parameters of ketamine calculated for RBC are equal or very similar to the plasma ones. The study confirms the kinetic behaviour of ketamine used in the horse as anaesthetic inducers in routine surgery. Finally, the bicompartmental model well describes the ketamine profile also in RBCs, that it is very close to the plasma profile, underlining the great importance of RBCs as blood subcompartment.
\end{abstract}

Keywords: Ketamine; Horse; Plasma; Red Blood Cells; Kinetics

\section{Introduction}

Ketamine (2-[2-chlorophenyl]-2-[methylamino]-cyclohexanone) is an arylcycloalkylamine structurally related to phencyclidine, presenting two enantiomeric forms, S$(+)$-ketamine and R-(-)-ketamine, with different anaesthetic potency [1]. Commercially it is available as a racemic mixture of hydrochloride salts. Ketamine is characterized by dissociative and analgesic properties. Firstly ketamine was used in humans as anaesthesia inducer, actually it is widely used also in Veterinary Medicine to induce anaesthesia in nearly all kinds of animals, including birds, primates and non-domesticated animals [2-6]. The mechanism of ketamine pharmacological action is related to its non-competitive antagonistic binding to the cation channel of the N-methyl-D-aspartate (NMDA)

\footnotetext{
"Corresponding author.
}

receptor, and its consequent interference with the excitatory amino acid transmitters, glutamate and aspartate [79].

In horses, ketamine has been used for more than two decades as an injectable anesthetic agent in conjunction with $\alpha 2$-adrenoceptor agonists such as xylazine. Ketamine is usually administered IV at a dose of $2.2 \mathrm{mg} \cdot \mathrm{kg}^{-1}$, usually producing an increase of cardiocirculatory parameters cause to its simpathetic effect [10]. Despite its extensive use in the horse, informations regarding the kinetic behaviour of ketamine in this species are not sufficiently updated [11-14].

Since ketamine is a lipophilic drug, it easily crosses cell membranes by means passive diffusion. Roncada et al. $[15,16]$ studied the pharmacokinetics of ketamine in cat and dog and its ability to bind and/or to store in red blood cells (RBCs), trying to explain the great variability 
in the response of both species to the same ketamine dosage, especially in relation to the recovery. Both studies highlighted the same good correlation between the levels of ketamine in plasma and those found in RBCs, suggesting the last fraction may be susceptible to several haematological factors (i.e. anaemia, complete blood count, $\mathrm{CBC}$ ) that, in part, may explain the underlined individual variability.

Erythrocytes, or red blood cells (RBCs), are derived from haemopoietic stem cells in bone marrow. They constitute the largest population of blood cells, they are small, flexible biconcave disks (the biconcave shape provides a large surface-to-volume ratio for oxygen delivery) containing haemoglobin, and are the main carriers of oxygen to the tissues, and $\mathrm{CO}_{2}$ back from the periphery to the lungs [17]. RBC membrane consists of a lipid bilayer (phospholipids, cholesterol) and proteins (including receptors, carriers, and enzymes); the cytosolic $\mathrm{pH}$ is 7.1 to 7.3 [18]. In addition to their $\mathrm{O}_{2}$ and $\mathrm{CO}_{2}$ transport ability, RBCs are easily crossed by small organic cationic, anionic, and nonelectrolytic molecules showing that lipophilicity, molecular size, and chiral characteristics are important. Lipophilic organic compounds penetrate the RBCs by their dissolution into the lipid bilayer membrane (passive diffusion) [18]. Owing to the ability of erythrocyte membranes to be opened and resealed, they provide an extraordinary vehicle for the dissemination of drugs in the circulation and represent potential vector and/or reservoir for different bioactive substances, including drugs and proteins [19,20].

This study was performed to match different purposes. The first one is to assess the plasma concentration of ketamine used as bolus to induce anaesthesia in horses during planned routine surgery. Secondly, the RBC partitioning of the anaesthetic drug was evaluated to assess also in this animal species possible consequences on the overall drug disposition profile. Finally, standing the high lipophilicity of ketamine and supposing to reach the partitioning equilibrium plasma/RBCs in a very short time, we verified if it would be possible to define also for RBCs the same kinetic parameters calculated for plasma, considering RBCs as a plasmatic "compartment" releaseing ketamine when it leaves circulation to distribute to tissues.

\section{Materials and Methods}

\subsection{Animals}

Ten healthy standardbred horses (two males and height females) $7.7 \pm 4.6$ (mean value \pm SD) years old and weighting $380 \pm 21 \mathrm{~kg}$ (mean value $\pm \mathrm{SD}$ ) were recruited. The animals were client-owned and were presented to undergo routine surgery at the Veterinary Teaching Hospital of the Department of Veterinary Medical Sciences.
The animals were allocated in individual box stalls. They were fasted 12 hours before surgery, and had free access to water until anaesthesia started. Preoperative haematobiochemical blood test results and clinical examinations of horses showed good general physical conditions. According to the American Society Anaesthesiology (ASA) classification, the horses were classified in the ASA I anaesthesiological risk class.

The study was handled according to the provisions of European Community (EC) Council Directive 86/609, adopted by the Italian Government (D.L. 27/01/1992 n. 116).

\subsection{Anaesthesiological Protocol}

A 14-G catheter, placed in the right jugular vein under local anaesthesia, was used for the administration of the drugs. The anaesthetic protocol was settled according the following succession: premedication with acepromazine $\left(0.04 \mathrm{mg} \cdot \mathrm{kg}^{-1} \cdot \mathrm{IV}\right.$; Prequillan ${ }^{\circledR}$, Fatro, Italy), and after 15 minutes, with romifidine $\left(0.08 \mathrm{mg} \cdot \mathrm{kg}^{-1} \cdot \mathrm{IV}\right.$; Sedivet ${ }^{\circledR}$, Boehringer-Ingelheim, Italy). Five minutes later, horses were administered midazolam $\left(0.06 \mathrm{mg} \cdot \mathrm{kg}^{-1} \cdot \mathrm{IV}\right.$; Ipnovel ${ }^{\circledR}$, Roche, Italy), and immediately, anaesthesia was induced by ketamine $\left(2.2 \mathrm{mg} \cdot \mathrm{kg}^{-1} \cdot \mathrm{IV}\right.$; Ketavet $100^{\circledR}$, Gellini, Italy) administered in quick succession. Following endotracheal intubation, horses were transported to the operating theatre by hoist, and connected to a large animal closed anaesthetic circle system. The anaesthesia was maintained with isoflurane (Isoflo Vet, Esteve, Italy) in $100 \%$ oxygen vehicle. Ringer lactate was administrated at $4 \mathrm{ml} \cdot \mathrm{kg}^{-1} \cdot \mathrm{h}^{-1}$ through the catheter in the jugular vein to replace the blood volumes withdrawn from the horse.

\subsection{Blood Sampling}

Blood samples $(5 \mathrm{ml})$ were collected by means a $14-\mathrm{G}$ catheter placed in the left jugular vein, immediately before ketamine administration (t0), and at 2, 5, 10, 15, 20, $25,30,40,50,60,75,90,105,120,150,180$ minutes after ketamine administration. All blood samples were immediately transferred in heparinised tubes and centrifuged $(1200 \times \mathrm{g})$ for 20 minutes at room temperature. After centrifugation, plasma was separated from RBCs; both biological matrices were transferred in clean test tubes and frozen at $-20^{\circ} \mathrm{C}$ until analysis.

\subsection{Ketamine Analyses}

The ketamine assay of plasma and RBCs was carried out at the Pharmacology and Toxicology Service in accordance with the Quality Management System of the Department certified ISO 9001.

The analytical method was set up and validated modifying the high performance liquid chromatographic (HPLC) 
analyses described by Gross et al. [21], especially concerning the liquid-liquid extraction steps.

Ketamine standard solution $\left(1 \mathrm{mg} \cdot \mathrm{mL}^{-1}\right)$ was purchased from Cerilliant Corporation (USA). Ketamine reference working standard solutions were prepared at different concentrations $\left(0.1 ; 0.25 ; 0.5 ; 1.0 ; 2.5 ; 5.0 ; 10.0 \mu \mathrm{g} \cdot \mathrm{mL}^{-1}\right)$ to generate a reference curve. In addition, plasma and RBCs related to the 0 time were spiked with ketamine reference standard solutions $(0.1 ; 0.25 ; 0.5 ; 1.0 ; 2.5 ; 5.0$; $10.0 \mu \mathrm{g} \cdot \mathrm{mL}^{-1}$ ) and subjected to the same extraction and purification procedures, as well as, HPLC analysis, of unknown samples (calibration curve).

The specificity and the linearity of the method were evaluated by repeating the analysis of the spiked samples in different days allowing the determination of mean coefficient of variation $(\mathrm{CV} \%)$. The limits of detection (LOD) and quantification (LOQ) were settled.

\subsection{Samples Preparation and Clean-Up}

Plasma: One thousand $\mu \mathrm{L}$ aliquots of plasma were acidified $(\mathrm{pH} \leq 2)$ by hydrochloric acid $(2.5 \mathrm{M}, 100 \mu \mathrm{L})$ in 15-mL conical glass screw-capped tubes, further $7 \mathrm{~mL}$ diethyl ether were added, and the mixture was tumbled using a rotatory mixer. Tubes were centrifuged $(1200 \times \mathrm{g}$, 5 minutes, room temperature) and the organic phase discarded. Sodium hydroxide $(5 \mathrm{~N}, 100 \mu \mathrm{L})$ was added to the acid phase up to $\mathrm{pH} \geq 12$, followed by a further diethyl ether $(7 \mathrm{~mL})$ extraction of the aqueous phase. After centrifugation $(1200 \times \mathrm{g}, 5$ minutes, room temperature), the organic layer was transferred to clean tubes $(10 \mathrm{~mL})$, and dried by a rotatory vacuum bench evaporator $\left(40^{\circ} \mathrm{C}\right.$, UNIVAPO; StepBio, Italy). The residue was reconstituted by orthophosphoric acid $(0.01 \mathrm{M}, 250 \mu \mathrm{L})$, and mixed by vortex (15 seconds) before transferring into HPLC-vials.

RBCs: One gram of RBCs was diluted with sodium dihydrogen phosphate buffer $(100 \mathrm{mM}, 5 \mathrm{~mL})$ and homogenized by Ultra-Turrax T25 (Janke and Kunkel, Italy). Aliquots of homogenate $(2 \mathrm{~mL})$, added to sodium hydroxide $(5 \mathrm{~N}, 400 \mu \mathrm{L})$, were transferred to conical glass screw-capped tubes $(15 \mathrm{~mL})$. The tubes were shortly vortex-mixed, extracted by adding diethyl ether $(7 \mathrm{~mL})$, and shaking using a rotatory mixer (10 minutes). After centrifugation $(1200 \times \mathrm{g}, 5$ minutes, room temperature) the organic phase was transferred to a clean tube $(10 \mathrm{~mL})$ containing sulphuric acid $(25 \mathrm{mM}, 250 \mu \mathrm{L})$, mixed (rotatory mixer, 10 minutes), and centrifuged $(1200 \times \mathrm{g}, 5$ minutes, room temperature). The organic phase was discarded, and the aqueous layer was dried in a rotatory vacuum bench evaporator $\left(40^{\circ} \mathrm{C}\right.$, UNIVAPO). The residue was reconstituted by orthophosphoric acid $(0.01 \mathrm{M}$, $200 \mu \mathrm{L}$ ), and mixed by vortex (15 seconds) before transferring it into HPLC-vials.

\subsection{Chromatography Assay}

A HPLC system (BeckmanCoulter SpA, Italy), comprising a 116 pump, a 507 automatic autosampler, an UVDiode Array 168 detector, and an integration software 32 karat, was used.

The mobile phase, consisting of a mixture methanolacetonitrile $(2.5: 1 \mathrm{v} / \mathrm{v})$ and orthophosphoric acid $(0.01 \mathrm{M})$ $(15: 85 \mathrm{v} / \mathrm{v})$, was at $0.8 \mathrm{~mL} \cdot \mathrm{min}^{-1}$ flow rate. The separation was performed using a reverse phase column Luna C18 $5 \mu \mathrm{m} 250 \times 4.6 \mathrm{~mm}$ (Phenomenex-Chemtek Analytica, Italy) with a pre-column PR C-18 $5 \mu \mathrm{m} 15 \times 4.6$ $\mathrm{mm}$ (Phenomenex-Chemtek Analytica, Italy). The HPLC injection size of samples was $50 \mu \mathrm{L}$. All chromatographic analyses were performed at room temperature.

\subsection{Pharmacokinetic Analysis}

Pharmacokinetic profiles were analyzed using the software package WinNonlin 4.0.1 (Pharsight Corporation, USA). Compartmental modelling was attempted for the plasma and RBC data, the best model was chosen on the basis of a visual inspection of the weighted residual plot. The pharmacokinetic parameters considered were: $A$ and $B$ (intercepts of the distribution and elimination phases), $\alpha$ and $\beta$ (the rate constants of distribution and elimination phases), $t_{1 / 2 \alpha}$ and $t_{1 / 2 \beta}$ (half lives of distribution and elimination phases), $A U C_{0 \rightarrow \infty}$ (the area under the curve to infinity), $\mathrm{Cl}$ (body clearance), $V d_{s s}$ (volume of distribution at steady-state), $C_{\max }$ (peak drug concentration), $A U M C$ (area under the first moment curve), MRT (mean residence time). Pharmacokinetic parameters were calculated for each animal.

\subsection{Statistical Analysis}

Pharmacokinetic parameters were presented as the median of single data (Microsoft Excel 2010). The plasma concentrations were plotted vs RBC concentrations using a linear regression to describe the relationship between the two variables $(\mathrm{P}<0.05)$ (Med calc 12.3.0 Software).

\section{Results}

During the course of anaesthesia (from sedation to recovery) all horses were healthy, the chosen anaesthesiological protocol (acepromazine, romifidine, midazolam, ketamine as induction, and isofluorane manintenence) perceived relative safety of dose and response.

\subsection{Ketamine Analysis}

To develop our method of analyses we started from the HPLC analyses described by Gross et al. [21]. Briefly, the modifications were essentially related to the liquid-liquid extraction steps of plasma. The early acidifica- 
tion, followed by the extraction with diethyl ether, discharging the organic phase, gave a clean sample (high sensitivity) with good recovery rate.

Concerning RBC, the weight of this biological material instead of prior dilution with sodium dihydrogen phosphate buffer, resulted in a highest accuracy despite the low RBC amounts. In addition, the dilution with sodium dihydrogen phosphate buffer, followed by the homogenization, brought the highest ketamine leakage.

The liquid-liquid extraction provided a good purification of plasma and RBCs with high mean recovery rates $(88.55 \% \pm 7.41 \%$, mean value $\pm \mathrm{SD} ; 75 \%$ in plasma and 96\% in RBC; CV\%: 7.2\%) in the considered concentration range. The high sensitivity was supported by ketamine LOD and LOQ. For plasma they were 0.025 $\mu \mathrm{g} \cdot \mathrm{mL}^{-1}$ and $0.050 \mu \mathrm{g} \cdot \mathrm{mL}^{-1}$, respectively; for RBCs they were $0.050 \mu \mathrm{g} \cdot \mathrm{mL}^{-1}$. The good linearity in the range of ketamine concentrations was supported by the high $\mathrm{R}^{2}$ coefficient $(>0.9998)$. These observations suggest a clinical applicability of the analytical method satisfying well the requirements of a kinetic study (wide range of concentrations). At the chromatographic conditions the ketamine retention time was about 20.5 minutes.

\subsection{Pharmacokinetics of Ketamine}

A bicompartmental model resulted as the most appropriate to describe the ketamine concentration-time profile for both plasma and RBCs. For all horses, the following equation was appropriate to describe the ketamine plasma and RBC concentrations:

$$
\mathrm{C}(t)=A \mathrm{e}^{-\alpha \mathrm{t}}+B \mathrm{e}^{-\beta \mathrm{t}}
$$

where $\mathrm{C}(t)$ is the plasma/RBC drug concentration at time $t$; e is the base of the natural logarithm; $A$ is the $y$-axis intercept and $\alpha$ is the slope for the distribution phase of the curve; $B$ is the $y$-axis intercept and $\beta$ is the slope for the elimination phase of the curve.

The pharmacokinetic parameters of ketamine in plasma and RBCs (medians) are summarized in Table 1, while the mean concentration-time profiles for ketamine in plasma and RBCs are shown in Figure 1.

$C_{\max }\left(4.1 \mu \mathrm{g} \cdot \mathrm{mL}^{-1}\right), A U C_{(0-\infty)}\left(58.3 \mathrm{~min} \cdot \mu \mathrm{g} \cdot \mathrm{mL}^{-1}\right)$, and AUMC (3525.2 $\mathrm{min} \cdot \mathrm{min} \cdot \mu \mathrm{g} \cdot \mathrm{mL}^{-1}$ ) made clear the high ketamine plasma levels. Observing the curves (Figure 1), the initial $\alpha$-phase of distribution decreased very rapidly $\left(\alpha 0.2 \mathrm{~min}^{-1}\right.$ ) and was characterized by a short distribution's half life $\left(\mathrm{t}_{1 / 2 \alpha} 3.5 \mathrm{~min}\right)$. The wide tissue distribution of ketamine was underlined by an "ideal" apparent volume of distribution at steady state (Vss $\left.1.9 \mathrm{~L} \cdot \mathrm{kg}^{-1}\right)$, suggesting that ketamine does not accumulate in tissues.

The elimination phase ( $\beta$-phase) was characterized by a lower slope $\left(\beta 0.01 \mathrm{~min}^{-1}\right)$, indicating a slow decline in blood levels of ketamine as a result of the elimination
Table 1. Plasma and RBC pharmacokinetic parameters (median), calculated for single IV administration of ketamine in horses.

\begin{tabular}{ccc}
\hline Parameter (units) & PLASMA & RBCs \\
\hline$\alpha\left(\mathrm{min}^{-1}\right)$ & 0.2 & 0.2 \\
$\beta\left(\mathrm{min}^{-1}\right)$ & 0.01 & 0.01 \\
$t_{1 / 2 \alpha}(\mathrm{min})$ & 3.5 & 3.5 \\
$t_{1 / 2 \beta}(\mathrm{min})$ & 71.0 & 85.8 \\
$A\left(\mu \mathrm{g} \cdot \mathrm{mL}^{-1}\right)$ & 3.9 & 4.3 \\
$B\left(\mu \mathrm{g} \cdot \mathrm{mL}^{-1}\right)$ & 0.4 & 0.3 \\
$C_{\max }\left(\mu \mathrm{g} \cdot \mathrm{mL}^{-1}\right)$ & 4.1 & 4.0 \\
$A U C_{(0-\infty)}\left(\mathrm{min} \cdot \mu \mathrm{g} \cdot \mathrm{mL}^{-1}\right)$ & 58.3 & 58.5 \\
$A U M C\left(\mathrm{~min} \cdot \mathrm{min}^{\prime} \mu \mathrm{g} \cdot \mathrm{mL}^{-1}\right)$ & 3525.2 & 2930.0 \\
$M R T(\mathrm{~min})$ & 80.2 & 71.5 \\
$V_{s s}\left(\mathrm{~L} \cdot \mathrm{kg}^{-1}\right)$ & 1.9 & 2.3 \\
$C l\left(\mathrm{~mL} \cdot \mathrm{min}^{-1} \cdot \mathrm{kg}^{-1}\right)$ & 11.6 & 13.1 \\
\hline
\end{tabular}

$A$ : the intercept and $\alpha$, the rate constant for the distribution phase of the curve; $B$ : the intercept and $\beta$, the rate constant for the terminal phase of the curve; $t_{1 / 2 \alpha}$ : distribution phase half-life; $t_{1 / 2 \beta}$ : elimination phase half-life; $C_{\max }$ : peak drug concentration; $A U C_{(0-\infty)}$ : area under plasma and RBCs concentration vs. time curve; $A U M C$ : area under the first moment curve; $M R T$ : mean residence time; $V_{s s}$ : volume of distribution at steady state; $\mathrm{Cl}$ : clearance.

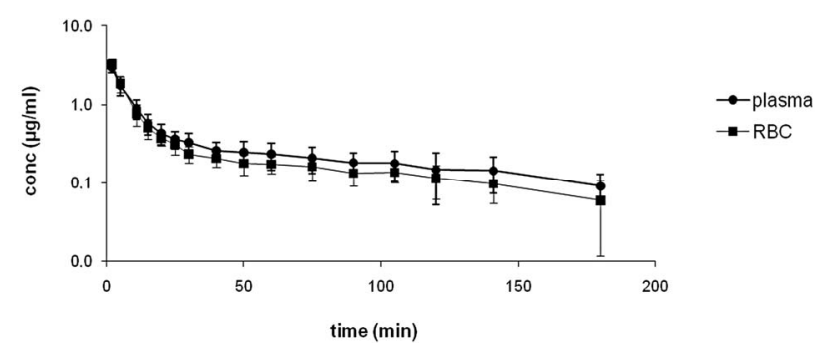

Figure 1. Ketamine concentrations-time profile (mean \pm SD) in plasma (•) and RBCs ( $\bullet$ ) after IV administration in horses.

processes (metabolism and excretion). The plasma $t_{1 / 2 \beta}$ was $71.0 \mathrm{~min}$, and the body clearance $\left(11.6 \mathrm{~mL} \cdot \mathrm{min}^{-1} \cdot \mathrm{kg}^{-1}\right)$ made it a fully significant reason for this slowdown. Ketamine was still detected at the last time of blood sampling (180 min).

In Figure 2, the diagram shows the fitted regression line between ketamine plasma concentrations and RBC concentrations for all the horses. The estimated regression equation was:

$$
\mathrm{y}=0.06836+1.0592 \mathrm{x}
$$

with a coefficient of determination $\left(\mathrm{R}^{2}\right)=0.9437$; a F-ratio $=2415.7$; a significance level $\mathrm{P}<0.0001$, and a Spearman's coefficient of rank correlation $=0.909$.

The kinetic parameters of ketamine calculated for $\mathrm{RBC}$ are equal or very similar to the plasma ones (Table 1). Only $t_{1 / 2 \beta}(85.8 \mathrm{~min})$ and $V_{s s}\left(2.3 \mathrm{~L} \cdot \mathrm{kg}^{-1}\right)$ were higher 


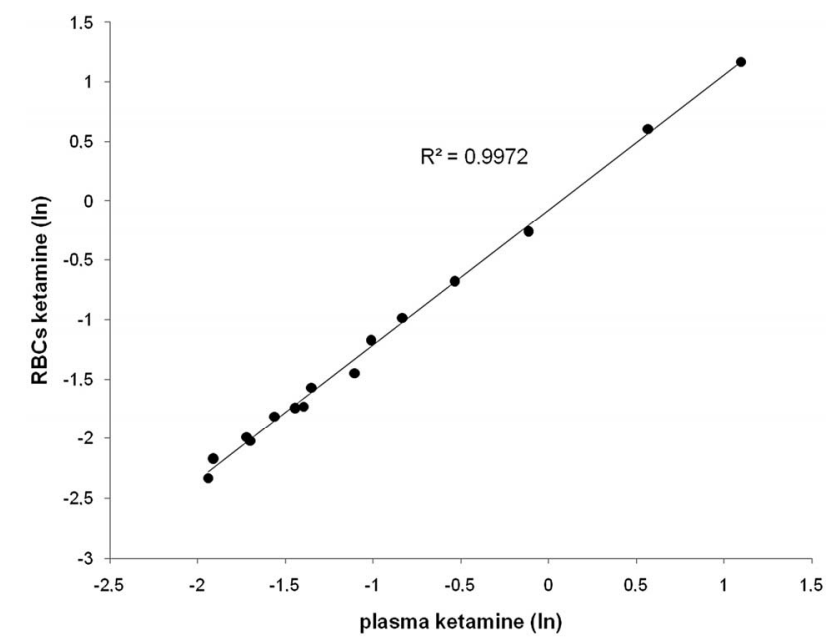

Figure 2. Representative linear relationship between ketamine concentrations in RBCs and ketamine concentrations in plasma of all horses.

than plasma, meanwhile, $A U M C\left(2930.0 \mathrm{~min} \cdot \mathrm{min} \cdot \mu \mathrm{g} \cdot \mathrm{mL}^{-1}\right)$ and $M R T$ (71.5 $\mathrm{min})$ were lower.

\section{Discussion}

The aims of the study, carried out in horse, were to assess the kinetic behaviour of ketamine used as bolus to induce anaesthesia during planned routine surgery; secondly to evaluate the plasma/RBC partitioning of the anaesthetic drug verifying possible consequences on the overall drug disposition profile. Finally, standing the high lipophilicity of ketamine, to check if it would be possible to define also for RBCs the same kinetic parameters calculated for plasma, considering RBCs as a plasmatic subcompartment.

The analytical method was specific, and sensitive enough to be implemented in studying the disposition kinetics of ketamine in blood and its RBC subcompartment. It is important to stress the relevance of the homogenization phase of red blood cells before the extraction of ketamine. Magnani et al. [22] underlined that human erythrocytes have the remarkable ability of their membrane to be opened and resealed providing an extraordinary possible vehicle for drugs. Thus, homogenization of RBC samples lets to the rupture of the $\mathrm{RBC}$ membranes excluding the possibility of resealing, and strengthening ketamine, making it difficult to extract.

The pharmacokinetic parameters were calculated for each individual animal, since the individual variability was wide, resulting in high standard deviations, we decide to present them as the median of single data.

An open bicompartmental model properly describes the trend of the plasmatic concentrations of ketamine that declined biexponentially (Figure 1), with a rapid distribution phase (half life $3.5 \mathrm{~min}$ ), followed by a slower elimination phase (half life $71.0 \mathrm{~min}$ ). The same bicom- partmental model was chosen by several Authors in kinetic studies concerning ketamine in horse, in cat, and in $\operatorname{dog}[11,12,15,16,23,24]$. Concerning the main kinetic parameters, our data (Table 1) fit well with results of other researches in the horse using ketamine in anaesthesiological protocols $\left(2.2 \mathrm{mg} \cdot \mathrm{kg}^{-1} \cdot \mathrm{IV}\right.$ as single bolus, or single bolus followed by ketamine infusion). In our trial MRT ( $80.2 \mathrm{~min})$ is lower than MRT defined by Flaherty et al. [24] and by Nolan et al. [23] (105.9 and $110.7 \mathrm{~min}$ respectively). The half life of the distribution phase $\left(t_{1 / 2 \alpha}\right.$ $3.5 \mathrm{~min})$ matches well with Waterman et al. [12] value $\left(t_{1 / 2 \alpha} 2.89 \pm 0.25 \mathrm{~min}\right)$. Differences are observed concerning the elimination phase $\left(t_{1 / 2 \beta} 71.0 \mathrm{~min}\right)$ versus data gained by Waterman et al. [12] $\left(t_{1 / 2 \beta} 65.84 \pm 3.46 \mathrm{~min}\right)$, and Flaherty et al. [24] ( $\left.t_{1 / 2 \beta} 46.1 \mathrm{~min}\right)$, but similarities are found with Nolan et al. [23] ( $\left.t_{1 / 2 \beta} 89.8 \mathrm{~min}\right)$. On the contrary, both Nolan et al. [23] and Kaka et al. [11] underlined $\mathrm{Cl}$ values higher than ours $\left(11.6 \mathrm{~mL} \cdot \mathrm{min}^{-1} \cdot \mathrm{kg}^{-1}\right)$. Finally, the volume of distribution at steady-state $\left(V_{s s} 1.9\right.$ $\mathrm{L} \cdot \mathrm{kg}^{-1}$ ) attains properly with data of Flaherty et al. [24], and of Nolan et al. [23] (1365 $\mathrm{ml} \cdot \mathrm{kg}^{-1}$, and $1.423 \mathrm{~L} \cdot \mathrm{kg}^{-1}$, respectively). Lots should be the reasons to explain these differences, mainly, the different anaesthesiological protocols (drugs used in pre-medication; simultaneous administration of other anaesthetics, i.e. propofol); but also the different age and weight of the horses have to take into consideration. In any case, the ketamine plasma behaviour is similar, as well as, the good course of anaesthesia (from sedation to recovery) described by all $\mathrm{Au}-$ thors. Thus, likewise Kaka et al. [11] and Waterman et al. [12] we can assume the duration of anaesthesia from a single $2.2 \mathrm{mg} \cdot \mathrm{kg}^{-1} \cdot \mathrm{IV}$ bolus of ketamine was determined largely by distribution; recovery from anaesthesia depends mainly on rapid redistribution of the drug from the central compartment (a 30\% - 40\% of the dose remains in the horse at recovery).

The fitted regression line between ketamine plasma and RBC concentrations (Figure 2) suggests that ketamine has the sufficient lipophilicity to pass the RBC membrane, and that, if vessels should be a "closed" system, equilibrium would be reached when the ratio of unbound concentrations of the drug in the aqueous phases of plasma and RBC cytosol remains constant. These data confirm the results of Roncada et al. in the cat [15] and in the dog [16], and highlight also in the horse the constant presence of the drug in the RBCs, at concentrations always comparable to those found in plasma (Figure 1), suggesting an equilibrium between the two compartments. This means that reequilibrium between the concentrations in the RBCs and plasma for lipophilic drugs, as ketamine, with significant RBC partitioning, occurs quickly and does not influence significantly the kinetic behaviour. In addition, we highlight that the RBC levels of ketamine declined biexponentially and have the same trend of the 
plasmatic ones (Figure 1). The kinetic parameters of ketamine obtained for RBC profile are equal or very close to the plasma ones (Table 1). Only $t_{1 / 2 \beta}(85.8 \mathrm{~min})$ and $V_{s s}\left(2.3 \mathrm{~L} \cdot \mathrm{kg}^{-1}\right)$ were higher than plasma, meanwhile, AUMC $\left(2930.0 \mathrm{~min} \cdot \mathrm{min} \cdot \mu \mathrm{g} \cdot \mathrm{mL}^{-1}\right)$ and $M R T(71.5 \mathrm{~min})$ were lower. RBCs can be considered a subcompartment of the blood, where ketamine apparently does not bind to RBC constituents, and it freely moves inside and outside only by passive diffusion. Thus we assume that the lower $A U M C$ and $M R T$ could support this hypothesis, while the higher RBC $t_{1 / 2 \beta}$ and $V_{s s}$ could validate the observations of Hinderling [18], Rossi et al. [20], and of Millán et al. [19] that consider RBCs as optimum vehicles/vectors and/or reservoirs for bioactive substances. Concerning ketamine, the RBCs could represent a kind of reservoir from which the anaesthetic is quickly released in circulation, without interferes apparently with its kinetic behaviour. Anyway, they become an important component in the mechanism of redistribution of a drug and it could assume a strong correlation for example with the hematocrit value (CBC). Therefore, $\mathrm{CBC}$ of the patient may be an important factor to consider in drug administration, especially when the drug, unlike ketamine, binds to RBCs bringing a possible accumulation phenomenon that could be responsible of the duration of the anesthesia, especially when the drug is used in continuous infusion, and especially in horses in relation to the risks of anaesthesia protocol (mortality $0.12 \%$ ) [25]. At this stage it would be interesting to confirm the precise location of ketamine inside RBCs identifying or excluding a possible binding to specific intracellular proteins.

Considering that in humans and animals, norketamine is considered as the major metabolite of ketamine (liver N-demethylation by cytochrome P450, mainly CYP3A4, CYP2B6 and CYP2C9 isoforms), and it may contribute to the anaesthetic and analgesic effects following ketamine administration [26-28], a further step of this study would be to detect the possible presence in RBCs of norketamine and/or other ketamine metabolites and to study their kinetic behaviour in RBCs, obtaining a complete picture on the pharmacokinetics of ketamine.

Our study confirms the kinetic behaviour of ketamine used in the horse as anaesthetic inducers in routine surgery, highlighting that the chosen anaesthesiological protocol (acepromazine, romifidine, midazolam, ketamine as induction, and isofluorane manintenence) perceived relative safety of dose and response (recovery). The plasma/ RBCs partitioning was settled also for ketamine, but it never modified its overall disposition profile. Finally the bicompartmental model well describes the ketamine profile also in RBCs, that it is very close to the plasma profile, underlining the great importance of RBCs as blood subcompartment, possible vehicles/vectors and/or reservoirs for drugs, and potential biological matrix, instead of whole blood, serum, or plasma, to increase the sensitivity of an assay to quantify, for example, drugs.

\section{REFERENCES}

[1] H. Koinig, P. Marhofer, C. Krenn, W. Klimsha, E. Wilding, W. Erlacher, A. Nikolic, K. Turnheim and M. Semsroth, "Analgesic Effect of Caudal and Intramuscular $\mathrm{S}(+)$-Ketamine in Children," Anesthesiology, Vol. 93, No. 4, 2000, pp. 976-980. doi:10.1097/00000542-200010000-00017

[2] EMEA, "Ketamine Summary Report," European Agency for the Evaluation of Medicinal Products, Committee for Veterinary Medical Products, 1997. http://www.ema.europa.eu/

[3] S. M. Green and B. Krauss, "Clinical Practice Guideline for Emergency Department Ketamine Dissociative Sedation in Children," Annals of Emergency Medicine, Vol. 44, No. 5, 2004, pp. 460-471. doi:10.1016/j.annemergmed.2004.06.006

[4] N. S. Matthews, C. L. Fielding and E. Swinebroad, "How to Use a Ketamine Constant Rate Infusion in Horses for Analgesia," Proceedings of the 50th Annual Convention of the American Association of Equine Practitioner, Vol. 50, 2004, pp. 227-228.

[5] M. Chauvin, "La Kétamine dans la Douleur Aiguë: De la Pharmacologie à la Clinique," Réanimation, Vol. 14, No. 8, 2005, pp. 686-691. doi:10.1016/i.reaurg.2005.10.014

[6] S. Himmelseher and M. E. Durieux, "Ketamine for Perioperative Pain Management," Anesthesiology, Vol. 102, No. 1, 2005, pp. 211-220. doi:10.1097/00000542-200501000-00030

[7] N. A. Anis, S. C. Berry, N. R. Burton and D. Lodge, "The Dissociative Anaesthetics, Ketamine and Phencyclidine, Selectively Reduce Excitation of Central Mammalian Neurones by N-methyl-D-aspartate," British Journal of Pharmacology, Vol. 79, No. 2, 1983, pp. 565-575. doi:10.1111/j.1476-5381.1983.tb11031.x

[8] G. Ellison, "The N-Methyl-D-Aspartate Antagonists Phencyclidine, Ketamine and Dizocilpine as Both Behavioural and Anatomical Models of the Dementias," Brain Research Reviews, Vol. 20, No. 2, 1995, pp. 250-267. doi:10.1016/0165-0173(94)00014-G

[9] P. Richebé, C. Rivat, B. Rivalan, P. Maurette and G. Simonnet, "Kétamine à Faibles Doses: Antihyperalgésique, Non-Analgésique," Annales Françaises d'Anesthésie, Vol. 24, No. 11, 2005, pp. 1349-1359. doi:10.1016/j.annfar.2005.07.069

[10] W. W. Muir, R. T. Skarda and D. W. Milne, "Evaluation of Xylazine and Ketamine Hydrochloride for Anesthesia in Horses," American Journal of Veterinary Research, Vol. 38, No. 2, 1977, pp. 195-201.

[11] J. S. Kaka, P. A. Klavano and W. L. Hayton, "Pharmacokinetics of Ketamine in the Horse," American Journal of Veterinary Research, Vol. 40, No. 7, 1979, pp. 978981.

[12] A. E. Waterman, S. A. Robertson and J. G. Lane, "Pharmacokinetics of Intravenously Administered Ketamine in 
the Horse," Research in Veterinary Science, Vol. 42, No. 2, 1987, pp. 162-166.

[13] P. M. Taylor, S. P. L. Luna, J. W. Sear and M. J. Wheeler, "Total Intravenous Anaesthesia in Ponies Using Detomidine, Ketamine and Guaiphenesin: Pharmacokinetics, Cardiopulmonary and Endocrine Effects," Research in Veterinary Science, Vol. 59, No. 1, 1995, pp. 17-23. doi:10.1016/0034-5288(95)90024-1

[14] M. P. Larenza, C. Peterbauer, M. F. Landoni, O. L. Levionnois, U. Schatzmann, C. Spadavecchia and W. Thotmann, "Stereoselective Pharmacokinetics of Ketamine and Norketamine after Constant Rate Infusion of a Subanesthetic Dose of Racemic Ketamine or S-Ketamine in Shetland Ponies," American Journal of Veterinary Research, Vol. 70, No. 7, 2009, pp. 831-839. doi:10.2460/ajvr.70.7.831

[15] P. Roncada, P. Pandolfi, V. Nigro, N. Romagnoli and A. Zaghini, "Ketamine Levels in Blood Corpuscular Fraction after Intramuscular Administration of the Dissociative Anaesthetic in the Cat: Preliminary Considerations," Proceedings of the 19th International Congress of the European Association for Veterinary Pharmacology and Toxicology (EAVPT), Journal of Veterinary Pharmacology and Therapeutics, Vol. 26, No. S1, 2003, pp. 209210.

[16] P. Roncada, N. Romagnoli, V. Nigro and A. Zaghini, "Ketamine Levels in Plasma and Red Blood Cells after Intravenous Administration in Dogs," Proceedings of the ISSX Meeting: Drug Metabolism and Disposition-From Molecular to Man, Drug Metabolism Reviews, Vol. 37, No. S1, 2005, p. 80.

[17] C. S. Olver, G. A. Andrews, J. E. Smith and J. J. Kaneko, "Erythrocyte structure and Function," In: Wiley-Backwell, Ed., Shalm's Veterinary Hematology, Douglas J. Weiss and K. Jane Wardrop Inc., 6th Edition, Ames, 2010, pp. 123-130.

[18] P. H. Hinderling, "Red Blood Cells: A Neglected Compartment in Pharmacokinetics and Pharmacodynamics," Pharmacological Reviews, Vol. 49, No. 3, 1997, pp. 279295.

[19] C. G. Millán, M. L. Sayalero Marinero, A. Z. Castaneda and J. M. Lanao, "Drug, Enzyme and Peptide Delivery Using Erythrocytes as Carriers," Journal of Controlled Release, Vol. 95, No. 1, 2004, pp. 27-49. doi:10.1016/i.jconrel.2003.11.018

[20] L. Rossi, S. Serafini, L. Cenerini, F. Picardi, L. Bigi, I.
Panzani and M. Magnani, "Erythrocyte-Mediated Delivery of Dexamethasone in Patients with Chronic Obstructive Pulmonary Disease," Biotechnology and Applied Biochemistry, Vol. 33, No. 2, 2001, pp. 85-89. doi:10.1042/BA20000087

[21] A. S. Gross, A. Nicolay and A. Eschalier, "Simultaneous Analysis of Ketamine and Bupivacaine in Plasma by High-Performance Liquid Chromatography," Journal of Chromatography B, Vol. 728, No. 1, 1999, pp. 107-115. doi:10.1016/S0378-4347(99)00097-3

[22] M. Magnani, L. Rossi, M. D’Ascenzo, I. Panzani, L. Bigi and A. Zanella, "Erythrocyte Engineering for Drug Delivery and Targeting," Biotechnology and Applied Biochemistry, Vol. 28, No. 1, 1998, pp. 1-6.

[23] A. Nolan, J. Reid, E. Welsh, D. Flaherty, R. McCormack and A. M. Monteiro, "Simultaneous Infusions of Propofol and Ketamine in Ponies Premedicated with Detomidine: A Pharmacokinetic Study," Research in Veterinary Science, Vol. 60, No. 3, 1996, pp. 262-266. doi:10.1016/S0034-5288(96)90051-X

[24] D. Flaherty, A. Nolan, J. Reid and A. M. Monteiro, "The Pharmacokinetic of Ketamine after Continuous Infusion under Halothane Anaesthesia in Horses," Veterinary Anaesthesia and Analgesia, Vol. 25, No. 8, 1998, pp. 31-36. doi:10.1111/j.1467-2995.1998.tb00166.x

[25] L. A. Bidwell, L. R. Bramlage and W. A. Rood, "Equine Perioperative Fatalities Associated with General Anaesthesia at a Private Practice-A Retrospective Case Series," Veterinary Anaesthesia and Analgesia, Vol. 34, No. 1, 2007, pp. 23-30. doi:10.1111/j.1467-2995.2005.00283.x

[26] J. S. Kaka and W. L. Hayton, "Pharmacokinetics of Ketamine and Two Metabolites in the Dog," Journal of Pharmacokinetics and Biopharmaceutics, Vol. 8, No. 2, 1980, pp. 193-202. doi:10.1007/BF01065193

[27] T. F. Wolf and J. D. Adams, "Biotransformation of Ketamine, (Z)-6-Hydroxyketamine and (E)-6-Hydroxy-Ketamine by Rat, Rabbit and Human Liver Microsomal Preparation,"Xenobiotica, Vol. 17, No. 7, 1987, pp. 839-847. doi: $10.3109 / 00498258709043993$

[28] M. Shimoyama, N. Shimoyama, A. L. Gorman, K. J. Elliot and C. E. Inturrisi, "Oral Ketamine Is Antinociceptive in the Rat Formalin Test: Role of the Metabolite, Norketamine," Pain, Vol. 81, No. 1-2, 1999, pp. 85-93. doi:10.1016/S0304-3959(98)00269-3 